\title{
Ultrasonic Peening Treatment Used to Improve Stress Corrosion Resistance of AlSi10Mg Components Fabricated Using Selective Laser Melting
}

\author{
Xiaodong Xing ${ }^{1, *} \mathbb{C}$, Xiaoming Duan ${ }^{1}$, Tingting Jiang ${ }^{2}$, Jiandong Wang ${ }^{2}$ and Fengchun Jiang ${ }^{2}$ \\ 1 College of Mechanical and Electrical Engineering, Harbin Engineering University, Harbin 150001, China; \\ 15603649190@163.com \\ 2 College of Materials Science and Chemical Engineering, Harbin Engineering University, Harbin 150001, \\ China; Sarah@hrbeu.edu.cn (T.J.); wangjiandong@hrbeu.edu.cn (J.W.); fengchunjiang@hrbeu.edu.cn (F.J.) \\ * Correspondence: xingxiaodong@hrbeu.edu.cn; Tel.: +86-451-8258-9251
}

Received: 25 December 2018; Accepted: 17 January 2019; Published: 19 January 2019

\begin{abstract}
As a rapidly evolving advanced digital manufacturing technology, additive manufacturing (AM) has its advantages including short manufacturing cycle, material saving, and complexity for free. It has great potential for application in marine and offshore engineering. However, stress corrosion damage will be a big threat for the additively manufactured metal parts in the ocean environment due to large residual stresses generated in the building process. This paper focuses on the effect of ultrasonic peening treatment (UPT) on stress corrosion resistance of AlSi10Mg components fabricated using Selective Laser Melting (SLM). Firstly, AlSi10Mg specimens were prepared using an SLM machine, and UPT was conducted on the specimen's top surface. Then, a series of measurements and analyses were carried out for the specimens before and after the UPT process. The residual stresses and hardness of the specimens were measured, and the surface morphology was observed using a scanning electron microscope (SEM). The resistance of stress corrosion was evaluated by the electrochemical corrosion test. The experimental results show that UPT can significantly improve stress corrosion resistance of SLM-fabricated specimens.
\end{abstract}

Keywords: ultrasonic peening treatment; stress corrosion resistance; selective laser melting; AlSi10Mg; laser additive manufacturing

\section{Introduction}

The aluminum alloy AlSi10Mg has good mechanical properties, including low density, high strength, and good wear resistance [1]. It is widely used in the field of ship and ocean engineering, such as high-speed hulls, deck chambers of warships, typical components on offshore platforms and marine transportation pipelines, etc. [2-5] Except for traditional manufacturing methods like casting, forging, and stamping processes, laser additive manufacturing technology is becoming a major processing method especially for aluminum parts with complex shapes and excellent performances. However, large residual stresses are generated inside the part due to the rapid melting and solidification of metal during the additively manufacturing process [6], which may lead to a decrease of stress corrosion resistance. Therefore, effective measures have to be adopted to eliminate residual stresses in aluminum alloy components fabricated using laser additive manufacturing.

At present, some approaches including optimization of processing strategy and parameters, substrate preheating, post-heat treatment, and hybrid post process are usually used to control the distribution and magnitude of the internal stress field of the laser additive manufacturing components, thereby improving the comprehensive performance of the components [6-8]. All the 
processing parameters, such as scanning speed, scanning strategy, laser power, and thickness, will affect the thermal stress distribution in the component. Optimization of the parameters according to different materials and processing conditions can effectively reduce the residual stress [9-11]. Some researchers monitor the temperature of the molten pool, deposited layers and powder bed in the building process, so as to adjust the processing parameters real time accordingly and obtain a relatively uniform temperature field and residual stress [12-14]. Buchbinder et al. [15] studied the effect of substrate preheating on the deformation of AlSi10Mg twin cantilevers fabricated using SLM and found that appropriate preheating can significantly reduce its deformation and residual stress. Kreitcberg et al. [16] explored the effect of post-heat treatment on mechanical properties and microstructures of Inconel 625 alloy parts built using SLM. Processes including shot peening, rolling, laser shock peening, and UPT are also used to modify the residual stress distribution of parts during or after the AM process [7,17-19]. UPT has the advantages of small size, strong controllability, and flexible application. It can transform tensile stress into beneficial compressive stress by plastically deforming the surface of components $[20,21]$. The fatigue life, surface hardness, and strength of components can be improved using UPT as well [22-24].

In this paper, UPT was used to relieve the residual stress of aluminum alloy specimens fabricated using SLM to improve the specimens' resistance ability to stress corrosion. The effects of UPT on the hardness, residual stress, and surface morphology were also studied.

\section{Experiments}

\subsection{Experiment Method}

Firstly, 12 AlSi10Mg specimens $(12 \mathrm{~mm} \times 12 \mathrm{~mm} \times 4.5 \mathrm{~mm})$ were prepared in one build using an SLM machine. The specimens were equally divided into two groups, one of which was subjected to a UPT process under the same conditions, and the other group was kept in an as-fabricated state for a comparative experiment. The surface morphology, material physical, and mechanical properties (hardness, residual stress) of the specimens were analyzed before and after the UPT process using scanning electron microscope, $\mathrm{X}$-ray stress diffraction, and a Vickers hardness test separately, and finally the electrochemical corrosion test was performed to investigate the stress corrosion resistance of the as-fabricated specimen and the UPT processed one. One specimen was examined in each test, and a total of eight specimens (four as-fabricated and four UPT processed ones) were required. The hardness and the residual stress values in each different surface along the specimen's thickness direction were measured at three different points in the same surface, and their arithmetic mean values were taken as the measured results, in order to reduce the measuring error.

\subsection{The Additive Manufacturing Process}

AlSi10Mg specimens $(12 \mathrm{~mm} \times 12 \mathrm{~mm} \times 4.5 \mathrm{~mm})$ are fabricated using an AFS-M260 SLM machine from Beijing Longyuan Automatic Forming System Co., Ltd., China. The chemical compositions of the base plate (5A06) and aluminum powder (AlSi10Mg) are listed in Table 1. The morphology of AlSi10Mg powder observed using a scanning electron microscope (SEM) is shown in Figure 1. First, the stereolithography (STL) file of the specimen model was sliced and imported into the machine. Then the substrate was preheated to $120^{\circ} \mathrm{C}$, and the oxygen concentration in the building chamber was reduced to below $1000 \mathrm{ppm}$. The processing parameters, such as laser power, scanning pattern, and layer thickness, were set as shown in Table 2.

Table 1. Chemical composition of forming material powder and base materials (wt $\%$ ).

\begin{tabular}{ccccccccc}
\hline Materials & Al & Si & Mg & Fe & Cu & Mn & Zn & Other \\
\hline AlSi10Mg & Balance & $9.0-10.0$ & $0.40-0.60$ & $\leq 2.0$ & $\leq 0.60$ & $\leq 0.35$ & - & $\leq 0.25$ \\
5A06 & Balance & 0.40 & $5.80-6.80$ & $\leq 0.40$ & $\leq 0.10$ & $0.5-0.8$ & $\leq 0.20$ & $\leq 0.10$ \\
\hline
\end{tabular}




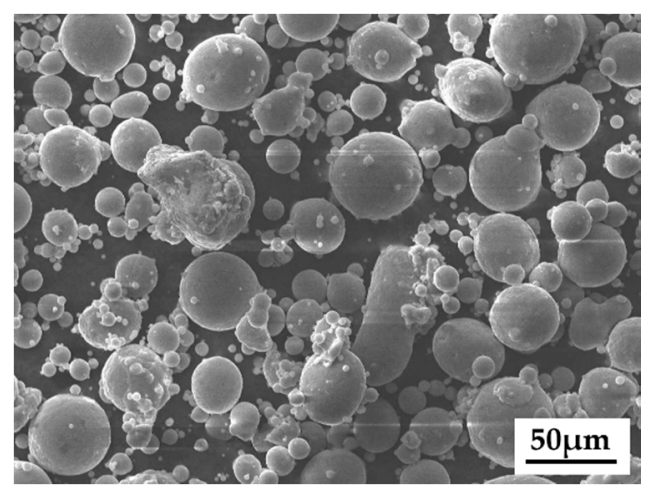

Figure 1. SEM morphologies of $\mathrm{Al} \mathrm{Si10Mg}$ powder.

Table 2. AM process parameters.

\begin{tabular}{ccccccc}
\hline Materials & Layer Thickness (mm) & Laser Power $(\mathrm{w})$ & Speed $(\mathrm{m} / \mathrm{s})$ & $\begin{array}{c}\text { Spot Diameter } \\
(\mathbf{m m})\end{array}$ & $\begin{array}{c}\text { Hatching } \\
\text { Space }(\mathrm{mm})\end{array}$ & $\begin{array}{c}\text { Scanning } \\
\text { Width (mm) }\end{array}$ \\
\hline AlSi10Mg & 0.03 & 200 & 1.8 & 0.07 & 0.06 & 4 \\
\hline
\end{tabular}

\subsection{UPT}

The specimens' surface was tested with high-frequency mechanical peening. As shown in Figure 2, the UPT device included a GCH-Q ultrasonic generator from Weihai Guosheng Ultrasonic Technology Co., Ltd., China, and its working principle is shown in Figure 3.

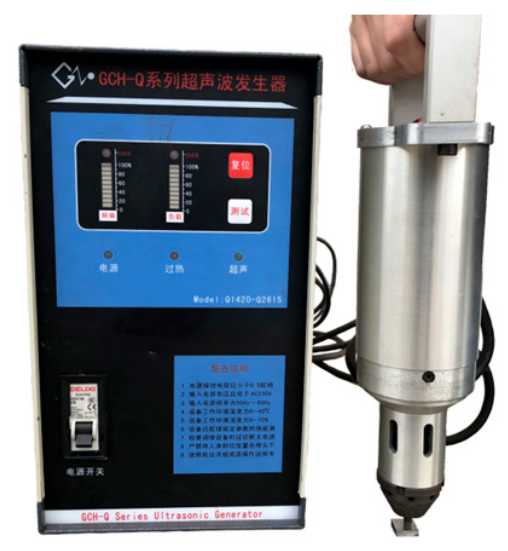

Figure 2. Photograph of UPT device.

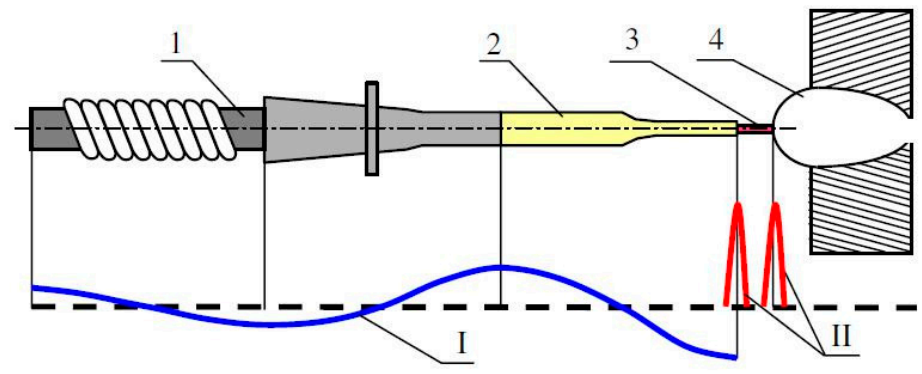

Figure 3. Schematic diagram of Esonix Ultrasonic Impact Treatment (UIT) (1-magnetostrictive transducer, 2-waveguide, 3-indenter, 4-treated surface, I-ultrasonic oscillations, II-impact impulses) [20] (Reproduced with permission from Elsevier, 2006).

It has been reported that the elliptical impact head produces more compressive stress than the square one [25]. An elliptical impact head is used in the experiment. During the impact process, the UPT device was moved manually throughout each specimen's entire top surface, with the impact head axis 
perpendicular to the surface. Parameters of the UPT process are shown in Table 3. The parameters used in the experiment were tailored to the mechanical properties of AlSi10Mg specimens empirically.

Table 3. Parameters of the UPT.

\begin{tabular}{ccccc}
\hline Frequency $(\mathrm{KHz})$ & Power $(\mathrm{W})$ & Amplitude $(\mu \mathrm{m})$ & Current $(\mathrm{A})$ & Impact Time $(\mathbf{s})$ \\
\hline $\mathbf{1 7}$ & 1000 & 80 & 2.2 & 60 \\
\hline
\end{tabular}

\subsection{Residual Stress Measurement}

The residual stress of the sample before and after the UPT was measured using X-ray diffraction (XRD), which is a non-destructive surface stress test method. In order to measure the specimen residual stress in each specimen's thickness direction, the electropolishing process was adopted to strip the specimens in the thickness direction examined in the experiment. The polishing solution was saturated $\mathrm{NaCl}$ solution, and the polishing process was based on ASTM standard: E1558-09.

\subsection{Hardness and SEM Test}

Hardness of the specimens was measured before and after the UPT using a Vickers hardness tester (Huayin Test Instrument Co., Ltd., Laizhou, China), and its basic hardness test parameters are shown in Table 4. A HITACHI S4300 scanning electron microscope (Hitachi, Tokyo, Japan) is used to observe the surface morphology of the specimens before and after UPT.

Table 4. Basic test parameters for hardness testing.

\begin{tabular}{cccc}
\hline Indenter Diameter (mm) & Loading Force (kgf) & Load Time (s) & Compress Time (s) \\
\hline 5 & 500 & 5 & 15 \\
\hline
\end{tabular}

\subsection{Electrochemical Corrosion Experiment}

The effect of the UPT on stress corrosion resistance of the SLM-fabricated specimens was studied by means of an electrochemical corrosion test. The preparation methods, dimensions, and material properties of the specimens used in the experiments are described above. Except for the specimen's top surface subjected to UPT, all the other surfaces were encapsulated with wax before the experiment. The electrochemical corrosion experiment was carried out using a CHI800D model electrochemical workstation produced by Shanghai Chenhua Instrument Co., Ltd., China. The experiment used a $3.5 \% \mathrm{NaCl}$ solution at room temperature and a standard three-electrode system, which included a working electrode (aluminum alloy specimen), a reference electrode (saturated calomel electrode), and an auxiliary electrode (platinum wire electrode). First, the open circuit potential of the specimen in the solution was tested. After it was stabilized, the potentiodynamic polarization curve and the electrochemical impedance spectrum (EIS) were measured. For electrochemical testing, the specified scan range of the potentiodynamic polarization curve was from $-1 \mathrm{~V}_{\text {sce }}$ to $0.5 \mathrm{~V}_{\text {sce }}$, and the scanning rate was $1 \mathrm{mV} / \mathrm{s}$. For the EIS measurement, the given scanning frequency was from $10 \mathrm{~Hz}$ to $100 \mathrm{kHz}$, a sinusoidal disturbance signal $(10 \mathrm{mV})$ was applied, and the test potential selected an open circuit potential. In order to demonstrate the effect of the UPT on the corrosion resistance of SLM-fabricated aluminum alloy specimens, both impact and non-impact specimens were tested in parallel under the same conditions.

\section{Results and Discussion}

\subsection{Effect of the UPT on Hardness}

Figure 4 shows the comparison of the Vickers hardness values of the specimen before and after the UPT. It can be seen from the figure that the hardness of the surface after the impact treatment 
increased by about $20 \%$ compared with the previous one, and the depth of action could reach $1.5 \mathrm{~mm}$ or more, which effectively improved the surface hardness value of the aluminum alloy specimen.

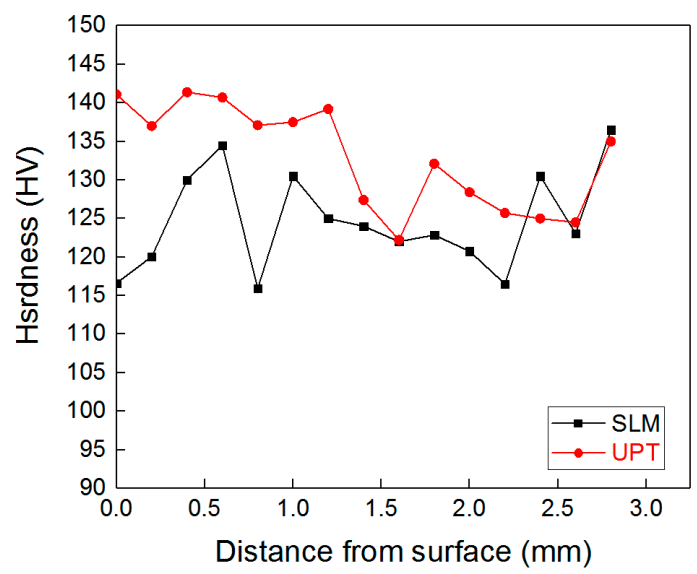

Figure 4. Hardness of specimens before and after UPT.

\subsection{Effect of the UPT on Residual Stress}

In order to study the effect of the UPT on the residual stress of aluminum alloy specimens fabricated using SLM, we measured the variation of the residual stress in each different top surface of the specimen after the stripping process along the thickness direction. The UPT can produce plastic deformation on the surface of the specimen. As a result, the tensile stress in the surface was transformed into compressive stress. Figure 5 shows the maximum conversion difference was $170 \mathrm{MPa}$. However, as the depth increased, the effect of action decreased, and the effective depth could reach $1.5-2 \mathrm{~mm}$. It was clear that the UPT had a positive effect on improving of the stress corrosion resistance of SLM-fabricated specimens from the point of view of the variation of the residual stress.

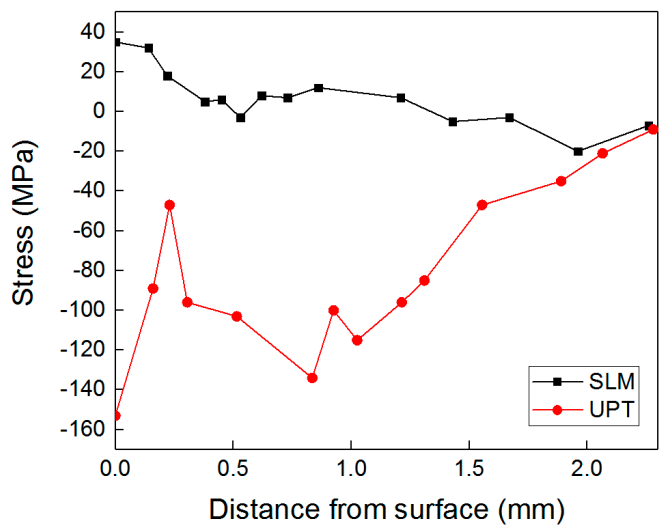

Figure 5. Residual stress in the specimen before and after UPT.

\subsection{Effect of the UPT on Surface Morphology of the Specimens}

The surface morphology of the specimens before and after the UPT was observed using a HITACHI S4300 SEM. The results are shown in Figure 6. 

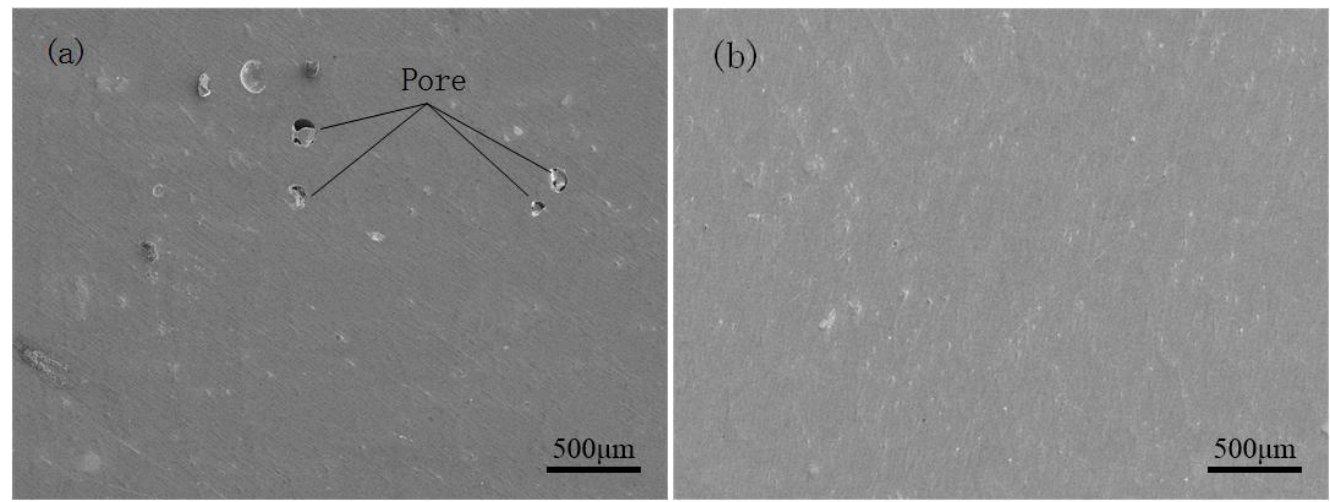

Figure 6. Surface morphology of AlSi10Mg specimens: (a) as-fabricated and (b) after the UPT.

It can be observed from Figure 6a that there were a small number of pores in the surface of the as-fabricated AlSi10Mg specimen, which may be attributed to inclusion of gas in the deposited layers during the melting and solidification process. Studies have shown that the gas in the process of building is mainly derived from the gas generated inside the powder or powder bed and evaporation of the material [26]. After the UPT process, it can be seen from Figure $6 \mathrm{~b}$ that there were almost no pores on the surface of the specimen. The reason was that plastic deformation occurred on its surface due to the UPT, which resulted in metal flow and closure of the pores. Through the above analysis, the UPT process reduced the porosity of the specimen and increased the density of the material, which is beneficial for improving the mechanical properties of the specimens.

\subsection{Stress Corrosion Behavior}

Figure 7 shows the polarization curves and EIS Nyquist of the as-fabricated specimens before and after the UPT in $3.5 \% \mathrm{NaCl}$ solution. It can be seen from Figure $7 \mathrm{a}$ that the polarization curves of the as-fabricated specimen before and after the UPT were very similar, which indicates that the corrosion processes in the two different cases were almost the same regardless of the the UPT process. The electrochemical parameters of corrosion potential $\left(\mathrm{E}_{\text {corr }}\right)$ and corrosion current density $\left(\mathrm{I}_{\text {corr }}\right)$ are shown in Figure 7a by analyzing the Tafel region of the polarization curve. Comparing the two curves in Figure 7a, it can be clearly seen that the potential $\mathrm{E}$ value of the specimen after the UPT was bigger than before the UPT with regard to the same current density value. However, there was no significant change in the $\mathrm{I}_{\text {corr }}$ values for specimen that were as-fabricated $\left(4.59 \times 10^{-8}\right)$ and /or after UPT $\left(5.26 \times 10^{-8}\right)$. According to the electrochemical theory, the smaller the $\mathrm{I}_{\text {corr }}$ and the larger the $\mathrm{E}_{\mathrm{corr}}$, the better the corrosion resistance. However, the self-corrosion voltage $\mathrm{E}_{\mathrm{corr}}$ is the main indicator when the deviation value of the $\mathrm{E}_{\text {corr }}$ exceeds $40 \mathrm{mV}$ in different cases [27]. Now the $\mathrm{E}_{\text {corr }}$ in the UPT case was $-0.486 \mathrm{~V}$, which was bigger than in the non-UPT case, and deviation value was 44 $\mathrm{mV}$. This indicates that the UPT process improved the stress corrosion resistance of the SLM-fabricated specimens. The EIS Nyquist curve is shown in Figure $7 \mathrm{~b}$. It can be seen from the Nyquist curve that the impedance value and radius of the specimens were significantly larger after the UPT. Generally, with the increase of impedance value and radius, polarization resistance increases and corrosion rate decreases. This means that the corrosion resistance of SLM-fabricated specimens can be improved using a UPT process. The conclusion drawn here is the same as in the previous sections. This may be attributed to two reasons: one is that the UPT process can increase the hardness in the surface layer, and the other is that the UPT process can transform tensile stress into compressive stress due to plastic deformation generated in the surface layer. 

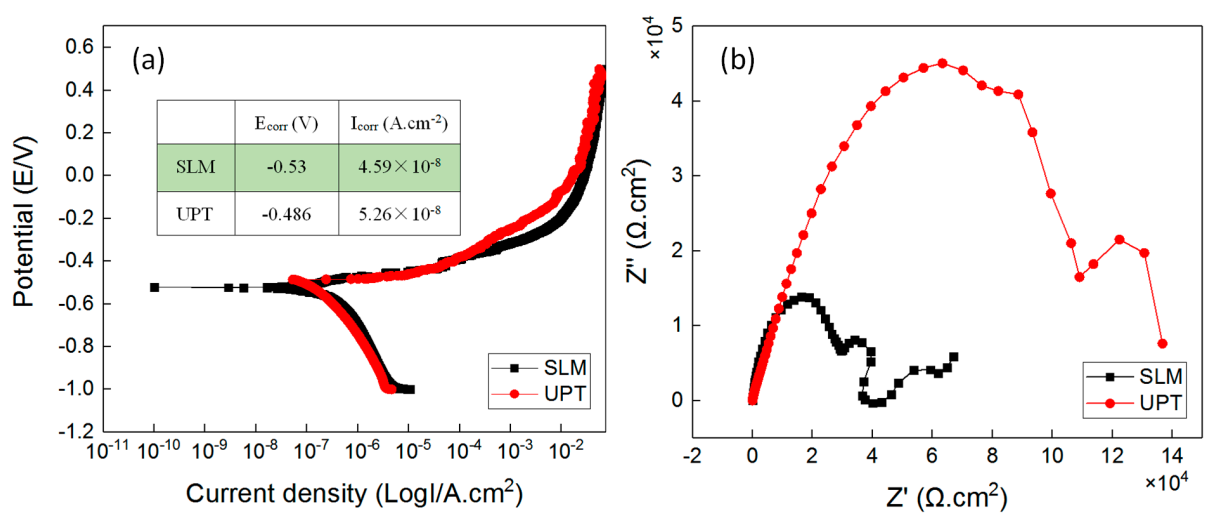

Figure 7. Stress Corrosion Properties of AlSi10Mg Aluminum Alloy (a) Polarization curve; (b) EIS Nyquist.

\section{Conclusions}

This paper presents the UPT process as an effective method to improve the stress corrosion resistance of aluminum alloy specimens fabricated using SLM. A series of experiments were implemented to investigate the UPT effect for laser additively manufactured specimens from different aspects. First, UPT effectively improved the surface hardness. Then, UPT changed the type of the residual stress, converting each specimen's surface tensile stress to compressive stress, where the depth of the effect could reach $1.5-2 \mathrm{~mm}$. It can be seen that the UPT reduced the porosity of AlSi10Mg specimens and improved the density of the material. All these effects contributed to the improvement of the stress corrosion resistance of the specimens. Furthermore, the electrochemical corrosion experiments were carried out to investigate the corrosion behavior of the specimens, which further verified that the stress corrosion resistance of the samples could be improved using a UPT process.

Author Contributions: X.X. and X.D. conceived and designed the experiments, analyzed the data, and conducted writing-original draft preparation, editing, visualization; X.D. performed the experiments; T.J., J.W. and F.J. contributed reagents, materials, and analysis tools.

Funding: This research was financially supported by the National Key Research and Development Program of China (2017YFB1103701), the Key Program for International S\&T Cooperation Projects of China (SQ2017YFGH001312).

Conflicts of Interest: The authors declare no conflict of interest.

\section{References}

1. Paik, J.K.; Van, D.V.S.; Duran, A.; Collette, M. Ultimate compressive strength design methods of aluminum welded stiffened panel structures for aerospace, marine and land-based applications: A benchmark study. Thin Wall. Struct. 2005, 43, 1550-1566. [CrossRef]

2. Paik, J.K.; Kim, B.J.; Sohn, J.M.; Kim, S.H.; Jeong, J.M.; Park, J.S. On Buckling Collapse of a Fusion-welded Aluminum-stiffened Plate Structure: An Experimental and Numerical Study. J. Offshore Mech. Arct. 2011, 134. [CrossRef]

3. Nakayama, G.; Kurebayashi, K.; Ooga, S.; Kanayama, T. Corrosion countermeasures for LNG storage tanks made of series 5083 aluminum-magnesium alloy. Surf. Interface Anal. 2016, 48, 721-728. [CrossRef]

4. Sielski, R.A. Research needs in aluminum structure. Ships Offshore Struct. 2008, 3, 57-65. [CrossRef]

5. Cerik, B.C. Damage assessment of marine grade aluminium alloy-plated structures due to air blast and explosive loads. Thin Wall. Struct. 2017, 110, 123-132. [CrossRef]

6. Mercelis, P.; Kruth, J.P. Residual stresses in selective laser sintering and selective laser melting. Rapid Prototyp. J. 2006, 12, 254-265. [CrossRef]

7. Sealy, M.P.; Madireddy, G.; Williams, R.E.; Rao, P.; Toursangsaraki, M. Hybrid Processes in Additive Manufacturing. J. Manuf. Sci. Eng. 2018, 140, 060801-060813. [CrossRef] 
8. Li, C.; Liu, Z.Y.; Fang, X.Y.; Guo, Y.B. Residual Stress in Metal Additive Manufacturing. Procedia CIRP 2018, 71, 348-353. [CrossRef]

9. Kumar, S. Selective laser sintering: A qualitative and objective approach. JOM 2003, 55, 43-47. [CrossRef]

10. Wu, A.S.; Brown, D.W.; Kumar, M.; Gallegos, G.F.; King, W.E. An Experimental Investigation into Additive Manufacturing-Induced Residual Stresses in 316L Stainless Steel. Metall. Mater. Trans. A 2014, 45, 6260-6270. [CrossRef]

11. Ali, H.; Ghadbeigi, H.; Mumtaz, K. Processing Parameter Effects on Residual Stress and Mechanical Properties of Selective Laser Melted Ti6Al4V. J. Mater. Eng. Perform. 2018, 27, 4059-4068. [CrossRef]

12. Berumen, S.; Bechmann, F.; Lindner, S.; Kruth, J.P.; Craeghs, T. Quality control of laser- and powder bed-based Additive Manufacturing (AM) technologies. Phys. Procedia 2010, 5, 617-622. [CrossRef]

13. Tapia, G.; Elwany, A. A Review on Process Monitoring and Control in Metal-Based Additive Manufacturing. J. Manuf. Sci. Eng. 2014, 136, 060801-060810. [CrossRef]

14. Tammas-Williams, S.; Zhao, H.; Léonard, F.; Derguti, F.; Todd, I.; Prangnell, P.B. XCT analysis of the influence of melt strategies on defect population in Ti-6Al-4V components manufactured by Selective Electron Beam Melting. Mater. Charact. 2015, 102, 47-61. [CrossRef]

15. Buchbinder, D.; Meiners, W.; Pirch, N.; Wissenbach, K.; Schrage, J. Investigation on reducing distortion by preheating during manufacture of aluminum components using selective laser melting. J. Laser Appl. 2014, 26, 012004. [CrossRef]

16. Kreitcberg, A.; Brailovski, V.; Turenne, S. Effect of heat treatment and hot isostatic pressing on the microstructure and mechanical properties of Inconel 625 alloy processed by laser powder bed fusion. Mater. Sci. Eng. A-Struct. 2017, 689, 1-10. [CrossRef]

17. Kalentics, N.; Boillat, E.; Peyre, P.; Ćirić-Kostić, S.; Bogojević, N.; Logé, R.E. Tailoring residual stress profile of Selective Laser Melted parts by Laser Shock Peening. Addit. Manuf. 2017, 16, 90-97. [CrossRef]

18. Uzan, N.E.; Ramati, S.; Shneck, R.; Frage, N.; Yeheskel, O. On the effect of shot-peening on fatigue resistance of AlSi10Mg specimens fabricated by additive manufacturing using selective laser melting (AM-SLM). Addit. Manuf. 2018, 21, 458-464. [CrossRef]

19. Hönnige, J.R.; Colegrove, P.A.; Ganguly, S.; Eimer, E.; Kabra, S.; Williams, S. Control of residual stress and distortion in aluminium wire + arc additive manufacture with rolling. Addit. Manuf. 2018, 22, 775-783. [CrossRef]

20. Statnikov, E.S.; Korolkov, O.V.; Vityazev, V.N. Physics and mechanism of ultrasonic impact. Ultrasonics 2006, 44, e533-e538. [CrossRef]

21. Ficquet, X.; Hedmar, M.; Kingston, E.J. Residual Stress Measurement in an Ultrasonic Peened Specimen. In Materials Technology, Proceedings of the 33rd International Conference on Ocean, Offshore and Arctic Engineering, San Francisco, CA, USA, 8-13 June 2014; Petroleum Technology: Stavanger, Norway, 2014; Volume 5.

22. Roy, S.; Fisher, J.W.; Yen, B.T. Fatigue resistance of welded details enhanced by ultrasonic impact treatment (UIT). Int. J. Fatigue 2003, 25, 1239-1247. [CrossRef]

23. Cheng, X.; Fisher, J.W.; Prask, H.J.; Gnäupel-Herold, T.; Yen, B.T.; Roy, S. Residual stress modification by post-weld treatment and its beneficial effect on fatigue strength of welded structures. Int. J. Fatigue 2003, 25, 1259-1269. [CrossRef]

24. He, C.; Yang, K.; Liu, Y.; Wang, Q.; Cai, M. Improvement of very high cycle fatigue properties in an AA7075 friction stir welded joint by ultrasonic peening treatment. Fatigue Fract. Eng. Mater. 2017, 40, 460-468. [CrossRef]

25. Yu, J.; Gou, G.; Zhang, L.; Zhang, W.; Chen, H.; Yang, Y.P. Ultrasonic Impact Treatment to Improve Stress Corrosion Cracking Resistance of Welded Joints of Aluminum Alloy. J. Mater. Eng. Perform. 2016, 25, 3046-3056. [CrossRef]

26. Kempen, K.; Thijs, L.; Van, H.J.; Kruth, J.P. Processing AlSi10Mg by selective laser melting: Parameter optimisation and material characterisation. Mater. Sci. Tech.-Lond. 2015, 31, 917-923. [CrossRef]

27. Dong, M.; Cui, X.; Jin, G.; Wang, H.; Cai, Z.; Song, S. Improved microstructure and properties of $12 \mathrm{Cr} 2 \mathrm{Ni} 4 \mathrm{~A}$ alloy steel by vacuum carburization and Ti+N co-implantation. Appl. Surf. Sci. 2018, 440, 660-668. [CrossRef]

(C) 2019 by the authors. Licensee MDPI, Basel, Switzerland. This article is an open access article distributed under the terms and conditions of the Creative Commons Attribution (CC BY) license (http:/ / creativecommons.org/licenses/by/4.0/). 